\title{
In the current era, complete revascularization improves survival after coronary artery bypass surgery
}

Thomas Kleisli, BS, Wen Cheng, MD, Milagros J. Jacobs, MPH, James Mirocha, MS, Michele A. DeRobertis, RN, Robert M. Kass, MD, Carlos Blanche, MD, Gregory P. Fontana, MD, Sharo S. Raissi, MD, Kathy E. Magliato, MD, and Alfredo Trento, MD

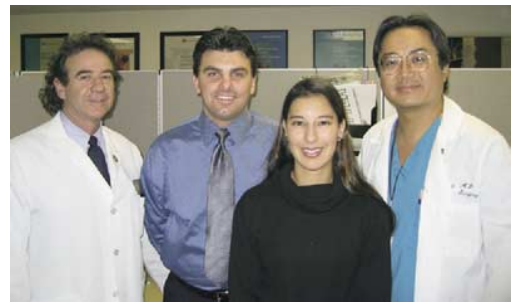

De Robertis, Kleisli, Jacobs, Cheng (left to right)

An appendix containing tables and illustrations is available online. $\mathcal{B}$
From the Division of Cardiothoracic Surgery, Cedars-Sinai Medical Center, Los Angeles, Calif.

Read at the Thirtieth Annual Meeting of The Western Thoracic Surgical Association, Maui, Hawaii, June 23-26, 2004.

Received for publication June 21, 2004; revisions received Dec 14, 2004; accepted for publication Dec 20, 2004.

Address for reprints: Wen Cheng, MD, Division of Cardiothoracic Surgery, CedarsSinai Medical Center, 8700 Beverly Blvd, North Tower, Suite 6215, Los Angeles, CA 90048 (E-mail: chengw@cshs.org).

J Thorac Cardiovasc Surg 2005;129:1283-91

$0022-5223 / \$ 30.00$

Copyright (c) 2005 by The American Association for Thoracic Surgery

doi:10.1016/j.jtcvs.2004.12.034
Background: Complete revascularization has been the standard for coronary bypass grafting. However, surgical intervention has evolved with increasing use of arterial conduits and off-pump techniques.

Methods: Patients undergoing non-redo bypass surgery from January 1998 through December 2000 were followed up with questionnaires and telephone contact. Incomplete revascularization was defined as absence of bypass grafts placed to a coronary territory supplied by a vessel with $50 \%$ or greater stenosis.

Results: One thousand thirty-four patients were followed for a mean of $3.3 \pm 1.6$ years. Complete revascularization was found in 937 (90.6\%) patients, and incomplete revascularization was found in $97(9.4 \%)$ patients. Eight hundred twenty-seven (80.4\%) patients underwent on-pump operations, and 207 (19.6\%) underwent offpump operations. Incomplete revascularization was more prevalent in off-pump versus on-pump operations $(21.7 \%$ vs $6.3 \%, P<.001)$. Multivariable Cox regression analysis indicated that in-hospital cerebrovascular accidents (hazard ratio, 5.49; $P<.001$ ), chronic obstructive pulmonary disease (hazard ratio, 1.97; $P=.019$ ), and incomplete revascularization (hazard ratio, $1.85 ; P=.040$ ) predicted an increased hazard (risk) of cardiac death. Left internal thoracic artery (hazard ratio, $0.38 ; P=.047$ ), right internal thoracic artery (hazard ratio, $0.25 ; P=.019$ ), and radial artery (hazard ratio, $0.36 ; P<.001$ ) grafting reduced the risk of cardiac death. The 5-year unadjusted survival rate was $52.6 \%$ versus $82.4 \%$ in patients undergoing incomplete and complete revascularization $(P<.001)$, with cardiac survival rates of $74.5 \%$ versus $93.1 \%$, respectively $(P<.001)$. However, this difference in cardiac survival was smaller in octogenarians with incomplete versus complete revascularizations $(77.4 \%$ vs $87.6 \%, P=.101)$ and was essentially absent in off-pump versus on-pump operations if complete revascularization was achieved in both cases (93.6\% vs $93.1 \%, P>.200)$.

Conclusions: Complete revascularization and arterial grafting improve 5-year survival. Off-pump techniques do not affect survival. Complete revascularization should be performed whenever possible.

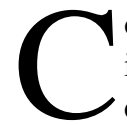
omplete myocardial revascularization is superior to incomplete revascularization, with greater long-term survival and freedom from reintervention in coronary artery bypass grafting (CABG). However, studies validating this were done in an earlier era with mainly saphenous vein grafting (SVG) and younger patient populations. ${ }^{1,2}$ Contemporary surgical studies question the benefits of complete revascularization (CRV) on long-term survival. ${ }^{3,4}$ Myocardial revascularization techniques have evolved in the last decade. Internal thoracic artery (ITA) bypass grafting is now the gold standard, and free radial arteries are increasingly used instead of saphenous veins. Off-pump cardiac surgical techniques have been 
adopted, with a consequence of more incomplete revascularization (IRV). ${ }^{5,6}$ The mean age of surgical patients is approaching 70 years, with an increasing number of 80year-old patients undergoing CABG. ${ }^{5}$ A re-evaluation of the importance of completeness of revascularization on outcomes after $\mathrm{CABGis}$ warranted.

\section{Patients and Methods}

All patients undergoing isolated non-redo CABGthrough a median sternotomy at Cedars-Sinai Medical Center between January 1, 1998, and December 31,2000,were analyzed. The preoperative coronary angiogram reports and the preoperative surgical consultations were used to determine the location of significant coronary artery obstructions in each patient. Type of conduit used and coronary vessels grafted were obtained from the surgical operative reports. All patients' data were entered into our cardiac surgical database, which follows 576 preoperative, intraoperative, and postoperative variables. Follow-up was conducted by using annual questionnaires and telephone contact to confirm outcomes. A total of 1034 patients were available for analysis.

\section{Completeness of Revascularization}

The definition of CRVis controversial. The traditional approach assumes one graft for every significantly obstructed coronary artery, whereas functional revascularization uses one graft for all diseased primary arterial territories. The left anterior descending artery (LAD)the circumflex artery, and the right coronary artery (RCA) define the coronary territories. Vander Salm and colleagues ${ }^{4}$ compared these 2 definitions in the Bypass Angioplasty Revascularization Investigation (BARI)study and found no significant survival advantage for either compared with patients with IRV.Most surgical groups have adopted the functional definition in their studies. ${ }^{1-3,6} \mathrm{We}$ used both a traditional and functional definition and found 101 patients versus 97 patients, respectively, with IRV.Of the 4 additional patients in the traditional group, 3 patients had 1 ungrafted circumflex marginal branch, and 1 patient had an ungrafted intermediate circumflex branch. This difference of 4 patients did not prove significant in any of the subsequent analyses. We therefore elected to use a functional definition to mirror other previous studies of completeness of revascularization.

The coronary vascular tree was divided into 3 separate territories: the LAD,the circumflex artery, and the RCA.One-territory disease was classified as an isolated $50 \%$ or greater diameter narrowing in at least 1 blood vessel supplying a single vascular territory. Two-territory disease involved $50 \%$ or greater vessel narrowing to 2 separate territories or isolated left main (LM) narrowing of $50 \%$ or greater not involving the RCA territory. Three-territory disease included $50 \%$ or greater vessel narrowing to all 3 territories or isolated LMnarrowing and RCAnarrowing together.

CRVwas achieved when at least one bypass graft was placed distal to a $50 \%$ or greater narrowing in each diseased territory. LM territory disease would require bypass grafting to both the LAD and the circumflex territory to be considered complete. Nongrafting of any significantly narrowed vascular territory was considered IRV.

\section{Study End Points}

The primary outcomes were all-cause and cardiac mortality occurring from the time of the operation through the last day of followup, May 1, 2004. The primary cause of death was categorized by the operating surgeon or the principal surgical investigator for the study (W.C.). Specific classifications for cause of death were cardiac and noncardiac. Cardiac causes of death included direct causes, such as sudden cardiac death, heart failure (pump), and arrhythmia (documented ventricular tachycardia or fibrillation). Secondary outcomes were reinterventions, including angioplasty, stenting, and reoperative CABG.In addition, we performed subgroup analyses of primary end points in patients 80 or more and less than 80 years of age.

\section{Statistical Analysis}

Results for continuous variables were expressed as mean + standard deviation. Results for categorical variables were expressed as number (percentage). Two-group differences for continuous and quasicontinuous variables were assessed by the independent-samples $t$ test, with adjusted degrees of freedom (Satterthwaite) when there was evidence against the homogeneity of variance assumption. Group differences for categorical variables were assessed by the $\chi^{2}$ and Fisher exact tests. Predictors of IRV were assessed by stepwise multivariable logistic regression. Odds ratios (ORs) with $95 \%$ confidence intervals were given for the predictor variables in the final logistic regression model. Nonparametric estimates of survival from all-cause and cardiac death were estimated for each comparison group by the Kaplan-Meier method. Group differences in survival functions were assessed by the log-rank test. Variables related to the hazards for all-cause and cardiac death were assessed by stepwise Cox proportional hazards models. The proportional hazards assumption was checked by assessing the interaction of time with each significant predictor in the Cox model and also by investigating the Schoenfeld residuals for each significant predictor. Hazard ratios (HRs) with $95 \%$ confidence intervals were given for the predictor variables in the final Cox models. A list of the candidate predictors for the stepwise analyses is contained in Table E1 (available online). Calculations were performed with SAS version 8.2 (SAS Institute, Cary, NC).

\section{Off-Pump Coronary Artery Bypass Learning Curve}

All operations involved 2 attending surgeons, serving as surgeon and first assistant surgeon, who performed the proximal and distal anastomoses. The 6 attending surgeons, who were present during the entire period of the study, participated in a minimum of 95 to a maximum of 149 cases through December 31, 2000. There was a gradual adoption of off-pump techniques, with $3.5 \%$ of off-pump coronary artery bypass (OPCAB) procedures performed in 1996, $9 \%$ in $1997,15.2 \%$ in $1998,28.1 \%$ in 1999 , and $26.4 \%$ in 2000 .

\section{OPCAB Patient Selection}

The choice of OPCAB versus on-pump CABG was the surgeon's preference. Factors favoring OPCAB included patients with suitable anatomy, epicardial target vessels of $1 \mathrm{~mm}$ or larger that were noncalcified and easy to expose, patients considered at high risk for cardiopulmonary bypass (CPB), elderly patients with multiple preoperative morbidities, and especially patients with significant calcification of the ascending aorta and vascular disease. 
Contraindications to OPCAB included technical issues, such as small, calcified, intramyocardial coronary targets. Difficulty in vessel exposure and unstable condition of the patient also precluded an off-pump approach. All 1034 operations were performed at Cedars-Sinai Medical Center.

\section{Surgical Technique}

OPCAB. A median sternotomy was used. Proximal and distal coronary artery flow was controlled with silicone rubber loops (Retract-O-Tape; Quest, Allen, Tex). Blood was cleared from the anastomotic site with a commercial carbon dioxide saline blower (Clearview blower/mister kit; Medtronic, Inc, Minneapolis, Minn). Commercial stabilizers included suction stabilizers (Medtronic Octopus I and II; Medtronic, Inc) and U-shaped foot stabilizers (Universal Stabilizers System; Estech Systems, Inc, Danville, Calif). A heparin dose of 10,000 units was given before vessel occlusion, and the activated clotting time was maintained at twice control activated clotting time. Heparin was fully reversed before sternal closure.

We selectively used coronary shunts (Flo-Thru intraluminal shunt; Bio-Vascular, Inc, St Paul, Minn), primarily in constructing bypass grafts to dominant RCAs. Exposure for lateral and inferior wall vessels was originally achieved by using a combination of deep pericardial stitches, an opening of the right side of the pericardium to the inferior vena cava-right atrial junction, and a right decubitus Tendelenburg position. Subsequently, apical suction stabilizers were used. Proximal anastomoses were made to the ascending aorta with the systolic blood pressure between 70 and 80 $\mathrm{mm} \mathrm{Hg}$ and a curved vascular clamp. If significant aortic calcification precluded safe clamp placement, proximal anastomoses were made to the side of the ITA.

Conventional $\boldsymbol{C A B G}$. CABG was performed through a median sternotomy during moderate hypothermia $\left(32^{\circ} \mathrm{C}\right)$ and $\mathrm{CPB}$ support. Single-dose, antegrade, cold blood cardioplegia was supplemented with cold, continuous, retrograde crystalloid cardioplegia and topical iced slush to protect the myocardium. Proximal anastomoses were performed during a single period of aortic crossclamping. The CPB circuit consists of a roller pump (Jostra Bentley Corp, Irvine, Calif) and membrane oxygenator (Avecor Affinity; Medtronic, Inc). Patients undergoing both OPCAB and on-pump CABG were discharged receiving either aspirin or warfarin sodium (Coumadin; DuPont Merck, Wilmington, Del) if their heart rhythm was classified as atrial fibrillation.

\section{Results}

Characteristics of subjects according to completeness of revascularization and use of CPB are shown in Tables 1 and 2. Follow-up was available for 1034 patients, with a mean of $3.3 \pm 1.6$ years. There were $97(9.4 \%)$ patients with IRV and 937 (90.6\%) patients with CRV. The mean age of the patients with IRV (71.7 \pm 12.1 years) was significantly greater than that of the patients with CRV $(67.4 \pm 10.8$ years, $P<.001$ ), with a greater proportion of octogenarians (24.7\% vs $11.2 \%, P<.001)$. The mean number of diseased territories was greater in the patients with IRV $(2.9 \pm 0.3 \mathrm{vs}$ $2.6 \pm 0.6, P<.001$; Table 1 ); however, the number of grafts placed was nearly 1 less per patient $(2.3 \pm 0.8$ vs 3.2 $\pm 0.9, P<.001$; Table 2). More than one fifth $(21.7 \%)$ of the patients undergoing OPCAB had IRV, which was significantly higher than in the on-pump CABG group $(6.3 \%$, $P<.001)$. Patients undergoing OPCAB tended to be older $(70.8 \pm 12.3$ vs $67.0 \pm 10.6$ years, $P<.001)$, with more octogenarians $(24.2 \%$ vs $9.6 \%, P<.001)$. Patients undergoing OPCAB also had fewer diseased territories $(2.2 \pm 0.8$ vs $2.8 \pm 0.4, P<.001)$ and nearly $1 \frac{1}{2}$ fewer bypass grafts $(2.0 \pm 0.7$ vs $3.4 \pm 0.8, P<.001$; Tables 1 and 2$)$.

\section{Reasons for IRV}

The most common reason recorded for IRV was that the arteries were too small, severely diseased, or both (Table E2). Nondominant RCA and the presence of prior infarcted tissue were the next most frequently recorded reasons. High surgical risk was cited only in 12 of the patients undergoing OPCAB. Significant collateral formation and lack of conduit availability were the next most frequent. Lack of a discernible reason was present only in 7 patients.

\section{Multivariable Regression Analysis}

Fifteen predictor variables were entered into a stepwise logistic regression analysis examining the determinants of IRV (see Table E1 [Appendix] for the list of predictor variables). The variables found to be significant in the final model included off-pump surgery (OR, 12.75; $P<.001)$, number of diseased coronary territories (OR, 11.61; $P<$ $.001)$, female sex (OR, 2.09; $P=.002)$, prior myocardial infarction (OR, 1.72; $P=.030$ ), and ejection fraction (OR, $0.98 ; P=.003$; Table 3 ).

There were 163 all-cause deaths, of which 68 were cardiac deaths. Nineteen variables were entered into the Cox proportional hazards regression analysis (see Table E1 [Appendix]). The variables found to be significant included in-hospital cerebrovascular accident (CVA; HR, 4.23; $P<$ .001 ), chronic obstructive pulmonary disease (HR, 2.12; $P<.001$ ), congestive heart failure (HR, 1.89; $P<.001$ ), IRV (HR, $1.73 ; P=.006)$, and age (HR, $1.03 ; P<.001$; Table 4). Use of right internal thoracic artery (RITA) grafts (HR, $0.51 ; P=.050$ ) and radial artery grafts (HR, $0.49 ; P$ $<.001)$ were associated with a lower risk of all-cause death.

Similar proportional hazards results were found for cardiac death, with in-hospital CVA (HR, 5.49; $P<.001$ ), chronic obstructive pulmonary disease (HR, 1.97; $P=$ .019 ), and IRV (HR, 1.85; $P=.040$ ) increasing the risk of cardiac death (Table 4). Age was no longer significantly important for cardiac death. A decreased risk of cardiac death was associated with an increase in ejection fraction (HR, 0.96; $P<.001$ ) and arterial grafting, including left internal thoracic artery (LITA; HR, 0.38; $P=.047$ ), RITA $(\mathrm{HR}, 0.25 ; P=.019)$ and radial artery $(\mathrm{HR}, 0.36 ; P<.001)$ grafting. 
TABLE 1. Baseline characteristics according to completeness of revascularization and use of cardiopulmonary bypass

\begin{tabular}{|c|c|c|c|c|c|c|}
\hline Characteristic & $\begin{array}{c}\text { Complete } \\
\text { revascularization } \\
(\mathbf{n}=937)\end{array}$ & $\begin{array}{c}\text { Incomplete } \\
\text { revascularization } \\
(\mathbf{n}=97)\end{array}$ & $P$ value & $\begin{array}{l}\text { On-pump } \\
(\mathrm{n}=827)\end{array}$ & $\begin{array}{c}\text { OPCAB } \\
(\mathrm{n}=\mathbf{2 0 7})\end{array}$ & $P$ value \\
\hline \multicolumn{7}{|l|}{ Demographics } \\
\hline Age (y) & $67.4 \pm 10.8$ & $71.7 \pm 12.1$ & $<.001$ & $67.0 \pm 10.6$ & $70.8 \pm 12.3$ & $<.001$ \\
\hline Age $\geq 80$ y & $105(11.2)$ & $24(24.7)$ & $<.001$ & $79(9.6)$ & $50(24.2)$ & $<.001$ \\
\hline \multicolumn{7}{|l|}{ Risk factors } \\
\hline Female & $232(24.8)$ & $36(37.1)$ & .010 & $216(26.1)$ & $52(25.1)$ & $>.200$ \\
\hline $\mathrm{DM}$ & $291(31.1)$ & $44(45.4)$ & .006 & $283(34.2)$ & $52(25.1)$ & .013 \\
\hline HTN & $615(65.6)$ & $65(67.0)$ & $>.200$ & $551(66.6)$ & $129(62.3)$ & $>.200$ \\
\hline COPD & $105(11.2)$ & $19(19.6)$ & .021 & $97(11.7)$ & $27(13.0)$ & $>.200$ \\
\hline PVD & $170(18.1)$ & $32(33.0)$ & .001 & $154(18.6)$ & $48(23.2)$ & .142 \\
\hline Acute MI & $151(16.1)$ & $28(28.9)$ & .003 & $147(17.8)$ & $32(15.5)$ & $>.200$ \\
\hline Urgent/emergency status & $307(33.0)$ & $42(42.4)$ & .074 & $283(34.4)$ & $66(32.0)$ & $>.200$ \\
\hline LVEF $<50 \%$ & $259(27.7)$ & $42(43.3)$ & .002 & $254(30.8)$ & $47(22.7)$ & .026 \\
\hline CHF (NYHA class III-IV) & $115(12.3)$ & $26(26.8)$ & $<.001$ & $107(12.9)$ & $34(16.4)$ & $>.200$ \\
\hline \multicolumn{7}{|l|}{ Diseased territories } \\
\hline LM & $232(24.8)$ & $32(33.0)$ & .087 & $214(25.9)$ & $50(24.2)$ & $>.200$ \\
\hline LAD & 868 (92.6) & $93(95.9)$ & $>.200$ & 768 (92.9) & $193(93.2)$ & $>.200$ \\
\hline$C x$ & $703(75.0)$ & $87(89.7)$ & $<.001$ & $690(83.4)$ & $100(48.3)$ & $<.001$ \\
\hline RCA & $761(81.2)$ & $94(96.9)$ & $<.001$ & $727(87.9)$ & $128(61.8)$ & $<.001$ \\
\hline \multicolumn{7}{|l|}{ No. of diseased territories } \\
\hline One territory & $55(5.9)$ & $0(0.0)$ & .007 & $8(1.0)$ & $47(22.7)$ & $<.001$ \\
\hline Two territories & $242(25.8)$ & $8(8.3)$ & $<.001$ & $171(20.7)$ & $79(38.2)$ & $<.001$ \\
\hline Three territories & $640(68.3)$ & $89(91.8)$ & $<.001$ & $648(78.4)$ & $81(39.1)$ & $<.001$ \\
\hline No. of territories diseased & $2.6 \pm 0.6$ & $2.9 \pm 0.3$ & $<.001$ & $2.8 \pm 0.4$ & $2.2 \pm 0.8$ & $<.001$ \\
\hline
\end{tabular}

Variables are expressed as mean \pm standard deviation or number (percentage). OPCAB, Off-pump coronary artery bypass; DM, diabetes mellitus; HTN, hypertension; COPD, chronic obstructive pulmonary disease; $P V D$, peripheral vascular disease; acute MI, myocardial infarction this admission; $L V E F$, left ventricular ejection fraction; $L M$, left main; $L A D$, left anterior descending; $C x$, circumflex; $R C A$, right coronary artery.

\section{Actuarial Survival Curves}

The Kaplan-Meier 5-year cumulative survival curves for subjects according to completeness of revascularization and CPB status are presented in Figures 1, 2, E1, and E2. Patients with IRV did significantly worse at 5 years than patients with CRV. However, patients undergoing off-pump CABG had similar survival as those undergoing on-pump CABG when both had CRV $(93.6 \%$ vs $93.1 \%, P>.200$; Figure 2, $B$ ).

\section{Discussion}

Complete myocardial revascularization is a long-held tenet of surgical coronary artery revascularization. Both a report from the Coronary Artery Surgery Registry in 1992 and from Emory University in 1996 established the long-term survival benefit of CRV in cardiac surgical patients. ${ }^{1,2}$ The Coronary Artery Surgery study followed 3372 patients undergoing isolated CABG between July 1974 and June 1979, among whom the mean age of patients was 56 years and in whom the saphenous vein was generally used, with $16 \%$ of patients receiving an ITA graft alone or in combination with saphenous veins. The 2860 Emory group patients enrolled between January 1978 and December 1981 were similar, with a mean age of 57 years and infrequent reported use of ITA grafting. These benchmark studies' major shortcoming is the infrequent use of arterial grafting in this earlier generation of younger patients.

More current studies, which use a greater percentage of arterial grafting, have called into question the benefit of CRV. Moon and associates ${ }^{3}$ reported that in octogenarian patients with increased ITA use (65\%), CRV did not improve survival. In the BARI study from August 1988 through August 1991, 1526 patients underwent CABG. The average age was 62 years, with more than $80 \%$ of the patients receiving ITA grafting. The BARI investigators were unable to demonstrate a survival advantage compared with IRV to 7 years of followup. ${ }^{4}$ Improvements in myocardial protection and more frequent ITA grafting might have decreased the survival benefit of CRV seen in an earlier era of primarily saphenous vein grafting. In addition, older patients might not live long enough to realize the benefits of CRV.

We observed 1034 patients undergoing isolated non-redo CABG at a single institution from January 1998 through December 2000. During this time span, there were few 
TABLE 2. Procedural characteristics and outcomes in relation to completeness of revascularization and use of cardiopulmonary bypass

\begin{tabular}{|c|c|c|c|c|c|c|}
\hline Characteristic & $\begin{array}{c}\text { Complete } \\
\text { revascularization } \\
(\mathrm{n}=937)\end{array}$ & $\begin{array}{c}\text { Incomplete } \\
\text { revascularization } \\
(\mathbf{n}=97)\end{array}$ & $P$ value & $\begin{array}{c}\text { On-pump } \\
(n=827)\end{array}$ & $\begin{array}{c}\text { OPCAB } \\
(n=207)\end{array}$ & $P$ value \\
\hline \multicolumn{7}{|c|}{ Procedural characteristics } \\
\hline CABG, on-pump & $775(82.7)$ & $52(53.6)$ & $<.001$ & - & - & - \\
\hline CABG, OPCAB & $162(17.3)$ & $45(46.4)$ & $<.001$ & - & - & - \\
\hline CABG, as CRV & - & - & - & $775(93.7)$ & $162(78.3)$ & $<.001$ \\
\hline CABG, as IRV & - & - & - & $52(6.3)$ & $45(21.7)$ & $<.001$ \\
\hline No. of grafts placed & $3.2 \pm 0.9$ & $2.3 \pm 0.8$ & $<.001$ & $3.4 \pm 0.8$ & $2.0 \pm 0.7$ & $<.001$ \\
\hline \multicolumn{7}{|l|}{ Territories grafted } \\
\hline LAD & $922(98.4)$ & $94(96.9)$ & $>.200$ & $816(98.7)$ & $200(96.6)$ & .067 \\
\hline Cx & $778(83.0)$ & $50(51.6)$ & $<.001$ & $752(90.9)$ & $76(36.7)$ & $<.001$ \\
\hline $\mathrm{RCA}$ & $761(81.2)$ & $32(33.0)$ & $<.001$ & $706(85.4)$ & $87(42.0)$ & $<.001$ \\
\hline \multicolumn{7}{|l|}{ Conduits used } \\
\hline LITA & 914 (97.6) & $94(96.9)$ & $>.200$ & $806(97.5)$ & $202(97.6)$ & $>.200$ \\
\hline RITA & $203(21.7)$ & $10(10.3)$ & .008 & $187(22.6)$ & $26(12.6)$ & .001 \\
\hline Radial artery & $550(58.7)$ & $37(38.1)$ & $<.001$ & $509(61.6)$ & $78(37.7)$ & $<.001$ \\
\hline Saphenous vein & 707 (75.5) & $58(59.8)$ & .001 & $681(82.4)$ & $84(40.6)$ & $<.001$ \\
\hline \multicolumn{7}{|l|}{ Complications } \\
\hline MI & $10(1.1)$ & $0(0.0)$ & $>.200$ & $10(1.2)$ & $0(0.0)$ & $>.200$ \\
\hline CVA & $19(2.0)$ & $7(7.2)$ & .008 & $21(2.5)$ & $5(2.4)$ & $>.200$ \\
\hline Mortality & $25(2.7)$ & $5(5.2)$ & .192 & $24(2.9)$ & $6(2.9)$ & $>.200$ \\
\hline \multicolumn{7}{|l|}{ Reinterventions } \\
\hline PTCA & $19(2.0)$ & $0(0.0)$ & $>.200$ & $16(1.9)$ & $3(1.5)$ & $>.200$ \\
\hline Surgical intervention & $2(0.2)$ & $1(1.0)$ & $>.200$ & $2(0.2)$ & $1(1.0)$ & $>.200$ \\
\hline
\end{tabular}

Variables are expressed as mean \pm standard deviation or number (percentage). OPCAB, Off-pump coronary artery bypass; $C A B G$, coronary artery bypass grafting; $C R V$, complete revascularization; $I R V$, incomplete revascularization; $L A D$, left anterior descending artery; $C x$, circumflex artery; $R C A$, right coronary artery; LITA, left internal thoracic artery; RITA, right internal thoracic artery; MI, myocardial infarction; CVA, cerebrovascular accident; Mortality, in-hospital mortality or 30-day mortality; PTCA, percutaneous transluminal coronary angioplasty.

changes in our surgical technique. OPCAB was well established at this time, with all of the surgeons familiar with its use. Radial artery and bilateral ITA grafting were frequently used techniques.

We found that patients with IRV had a decreased longterm survival out to 5 years when compared with patients with CRV. However, the survival benefit of CRV was less in octogenarians. The 5-year survival was better but did not reach clinical significance. The major benefit of CRV was seen in patients less than 80 years of age. This makes sense because these patients have a longer expected survival, and there were more patients available to statistically confirm any difference in outcome.

One of the most striking features in the follow-up is the magnitude of the survival difference between patients with CRV and patients with IRV out to 5 years. The survival curves progressively diverge throughout the 5-year period. IRV certainly accounts for a significant proportion of this. However, the type of grafting might also play a significant role. Nearly everyone received a LITA graft. In addition, patients with CRV received significantly more arterial grafting with RITAs and radial arteries. In the Cox proportional hazards analysis,
IRV increased the chance of cardiac and all-cause death between $70 \%$ and $80 \%$. Receiving a radial artery graft, RITA graft, or both decreased the chance of all-cause death about $50 \%$ and cardiac death between $60 \%$ and $80 \%$.

We also found more IRV in patients undergoing OPCAB.${ }^{5,6}$ Although some experienced OPCAB surgeons have demonstrated the ability to achieve $100 \%$ CRV in these patients, ${ }^{7}$ most series confirm a near doubling of IRV

TABLE 3. Predictors of incomplete revascularization: Results of multivariable logistic regression

\begin{tabular}{lrlr}
\hline & \multicolumn{3}{c}{ Multivariable } \\
\cline { 2 - 4 } Incremental risk factors & OR & 95\% CI & $\boldsymbol{P}$ value \\
\hline Off-pump & 12.75 & $7.49-22.72$ & $<.001$ \\
No. of territories diseased & 11.61 & $5.33-25.27$ & $<.001$ \\
Female sex & 2.09 & $1.37-3.66$ & .002 \\
Prior MI & 1.72 & $1.05-2.82$ & .030 \\
EF & 0.98 & $0.97-0.99$ & .003
\end{tabular}

$O R$, Odds ratio; $C l$, confidence interval; $M I$, myocardial infarction; $E F$, ejection fraction. 
TABLE 4. Predictors of death: Cox proportional hazards model

\begin{tabular}{|c|c|c|c|c|c|c|}
\hline \multirow[b]{2}{*}{ Incremental risk factors } & \multicolumn{3}{|c|}{ All-cause death } & \multicolumn{3}{|c|}{ Cardiac death } \\
\hline & HR & $95 \% \mathrm{CI}$ & $P$ value & HR & $95 \% \mathrm{CI}$ & $P$ value \\
\hline CVA, in-hospital & 4.23 & $2.46-7.27$ & $<.001$ & 5.49 & $2.41-12.51$ & $<.001$ \\
\hline COPD & 2.12 & $1.47-3.06$ & $<.001$ & 1.97 & $1.12-3.48$ & .019 \\
\hline $\mathrm{CHF}$ & 1.89 & $1.33-2.69$ & $<.001$ & - & - & - \\
\hline IRV & 1.73 & $1.18-2.55$ & .006 & 1.85 & $1.03-3.34$ & .040 \\
\hline Age & 1.03 & $1.02-1.05$ & $<.001$ & - & - & - \\
\hline $\mathrm{EF}$ & 0.98 & $0.97-0.99$ & $<.001$ & 0.96 & $0.95-0.98$ & $<.001$ \\
\hline LITA & - & - & - & 0.38 & $0.15-0.99$ & .047 \\
\hline RITA & 0.51 & $0.26-1.00$ & .050 & 0.25 & $0.08-0.80$ & .019 \\
\hline Radial artery & 0.49 & $0.34-0.70$ & $<.001$ & 0.36 & $0.21-0.64$ & $<.001$ \\
\hline
\end{tabular}

$H R$, Hazard ratio; $C l$, confidence interval; $C V A$, cerebrovascular accident; COPD, chronic obstructive pulmonary disease; $C H F$, congestive heart failure; IRV, incomplete revascularization; $E F$, ejection fraction; LITA, left internal thoracic artery; RITA, right internal thoracic artery.

in the setting of OPCAB. ${ }^{5,6}$ The worse clinical outcomes seen in OPCAB were due to this higher prevalence of IRV. We did not observe an increase in cardiac mortality for patients undergoing OPCAB if they received CRV.

We examined the reasons for IRV in our patients to see whether there was a rationale for the higher incidence of IRV seen in our patients undergoing OPCAB. The patients undergoing on-pump bypass who were incompletely revas- cularized typically gave reasons that minimized the importance of nongrafting, such as small and/or severe disease, nondominant RCA, prior infarcted myocardium, or the presence of collateral vessels. This represented $85 \%$ of stated reasons for IRV in the on-pump group. The remaining $15 \%$ were lack of conduit availability and "no reason given." The patients undergoing OPCAB with IRV had only $55 \%$ of reasons that minimized nongrafting. However, about a quar-
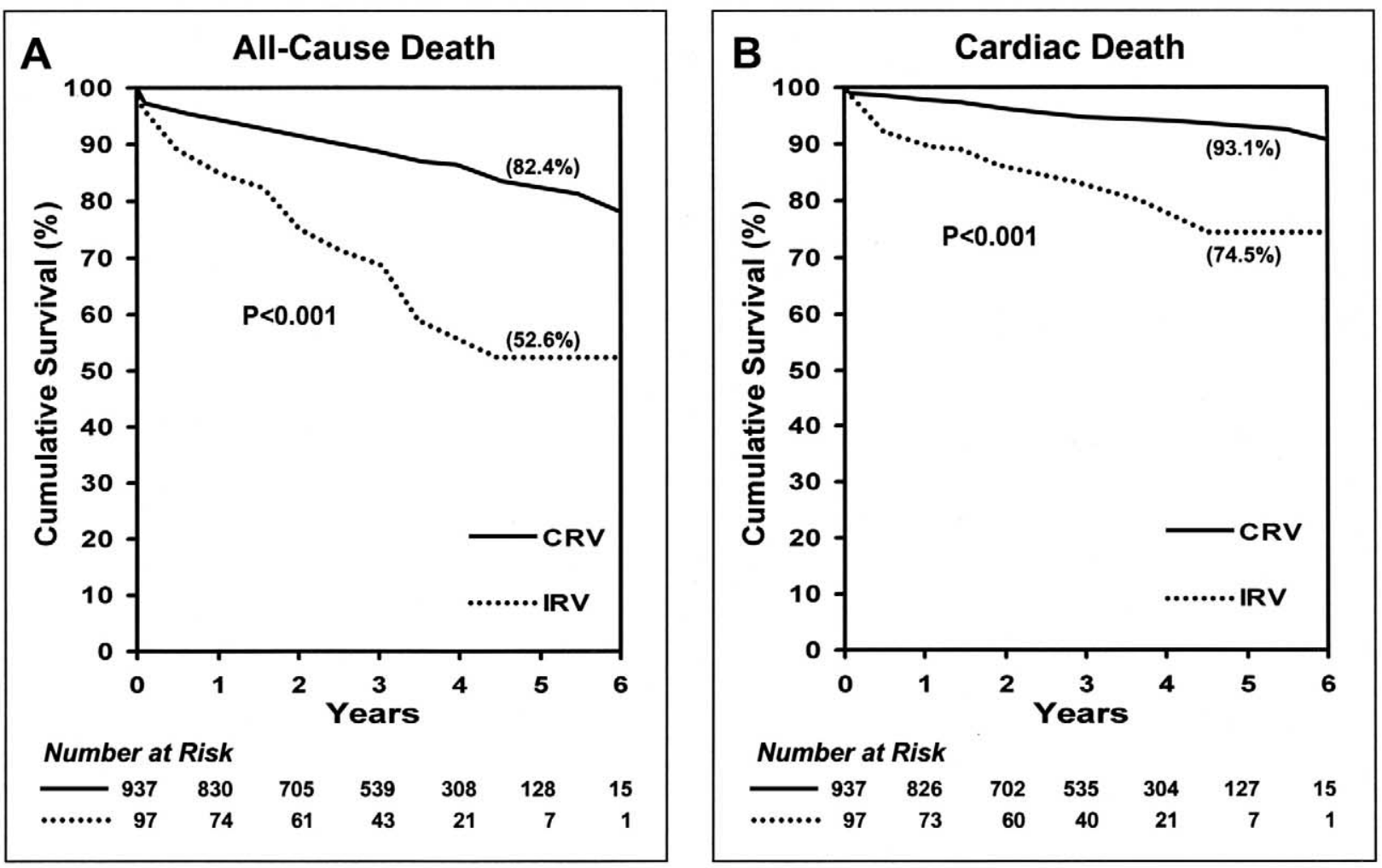

Figure 1. A, Cumulative unadjusted survival from all-cause death in patients with CRV and IRV. B, Cumulative unadjusted survival from cardiac death in patients with IRV and CRV. Numbers in parentheses (percentages) represent 5-year survival percentages. 

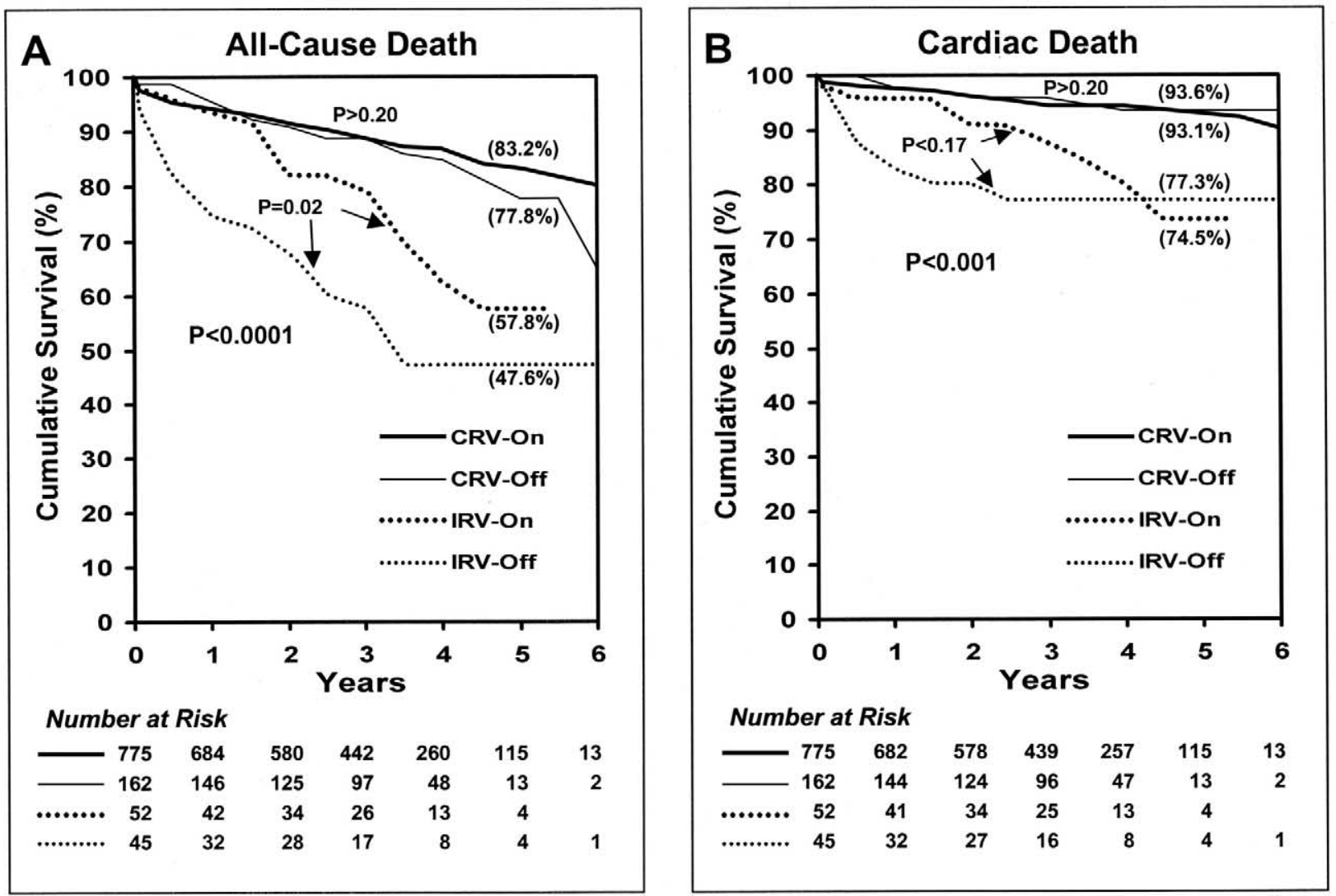

Figure 2. A, Cumulative unadjusted survival from all-cause death for patients undergoing on-pump (On) and off-pump (Off) CABG and patients with CRV and IRV. B, Cumulative unadjusted survival from cardiac death for patients undergoing on-pump (On) and off-pump (Off) CABG and patients with CRV and IRV. Numbers in parentheses (percentages) represent 5-year survival percentages.

ter (12 patients) were considered high risk, and a preoperative decision was made to do a simpler operation of OPCAB to anterior wall targets, leaving the lateral wall, inferior wall, or both ungrafted. However, this difference in stated reasons for IRV between the on-pump and OPCAB groups did not result in a difference in cardiac survival (Figure $2, B$ ). It seems that at least a percentage of patients undergoing OPCAB had IRV planned preoperatively. When having undertaken OPCAB operations, our cardiac surgeons were more likely to leave territories incompletely revascularized, although not always indicating specific reasons. The reason for choosing OPCAB was surgeon preference and was frequently not explained in the medical record.

IRV had a significant negative effect on patient survival and should be avoided when possible. Whether this is achieved with an on-pump or off-pump technique is unimportant. In addition, arterial grafting with the LITA, the RITA, and the radial artery independently improve survival. We currently attempt to maximize the benefits of arterial grafting by using more sequential LITA grafts, as well as RITA grafts, for both left- and right-sided targets. The radial artery of the nondominant extremity, if the result of the Allen test is normal, has become our preferred conduit versus the saphenous vein. Bilateral radial artery use has become increasingly used. By using these multiple arterial conduits, it is presently rare that we are unable to completely revascularize our patients. We continue to use OPCAB for patients we consider at high risk for $\mathrm{CPB}$, such as patients with calcified aortas and older patients with prior CVAs and anyone with significant carotid disease. However, we currently place greater emphasis on completely revascularizing all patients undergoing OPCAB with the aid of apical suction stabilizer's for better access to the inferior and lateral walls of the heart. In the unstable high-risk patient in whom grafting of the lateral wall is difficult or impossible, we have achieved CRV with a hybrid procedure consisting of off-pump grafting of accessible anterior wall targets and balloon angioplasty and stenting of lateral and inferior wall targets. 


\section{Study Limitations}

Our study is subject to all the limitations inherent in a retrospective review. There was significant selection bias in choosing which patients received CRV and IRV and OPCAB versus on-pump CABG techniques. To minimize these biases, we chose to analyze both all-cause death and cardiac death. Cardiac death as an outcome variable should be more closely linked to completeness of revascularization than all-cause death. Multivariable logistic and Cox regression analyses were then used to adjust for confounding risk factors. However, these methods cannot entirely eliminate biases in an observational study.

Other potential limitations include the relatively small numbers of patients in the subgroup analysis of patients 80 years of age or older and in the OPCAB patients with CRV and IRV, as well as the small number of cardiac deaths, of which we had 68. Preoperative coronary angiogram reports might not be as accurate as systematic interpretation by a single group of experienced readers.

\section{Conclusions}

CRV remains desirable, even in the current era of arterial grafting and OPCAB techniques. In fact, arterial grafting appears to improve survival in patients undergoing $\mathrm{CABG}$ independent of the completeness of revascularization. The survival benefit of CRV seems greater in patients less than 80 years of age. IRV is more prevalent in OPCAB operations. However, similar results can be achieved in OPCAB operations if patients are completely revascularized. Patients undergoing CABG should have CRV with arterial grafts to maximize survival.

\section{References}

1. Bell MR, Gersh BJ, Schaff HV, Holmes DR, Fisher LD, Alderman EL, et al. Effect of completeness of revascularization on long-term outcome of patients with three-vessel disease undergoing coronary artery bypass. A report from the Coronary Artery Surgery Study (CASS) Registry. Circulation. 1992;86:446-57.

2. Jones EL, Weintraub WS. The importance of completeness of revascularization during long-term follow-up after coronary artery operations. J Thorac Cardiovasc Surg. 1996;112:227-37.

3. Moon MR, Sundt TM, Pasque MK, Barner HB, Gay WA, Damiano RJ. Influence of internal mammary artery grafting and completeness of revascularization on long-term outcome in octogenarians. Ann Thorac Surg. 2001;72:2003-7.

4. Vander Salm TJ, Kip KE, Jones RH, Schaff HV, Shemin RJ, Aldea GS, et al. What constitutes optimal surgical revascularization? Answers from the Bypass Angioplasty Revascularization Investigation (BARI). J Am Coll Cardiol. 2002;39:565-72.

5. Cheng W, Denton TA, Fontana GP, Raissi S, Blanche C, Kass RM, et al. Off-pump coronary surgery: effect on early mortality and stroke. J Thorac Cardiovasc Surg. 2002;124:313-20.

6. Sabik JF, Gilinov AM, Blackstone EH, Vacha C, Houghtaling PL, Navia J, et al. Does off-pump coronary surgery reduce morbidity and mortality? J Thorac Cardiovasc Surg. 2002;124:698-707.

7. Puskas JD, Williams WH, Duke PG, Staples JR, Glas KE, Marshall JJ, et al. Off-pump coronary artery bypass grafting provides revascularization with reduced myocardial injury, transfusion requirements, and length of stay: a prospective randomized comparison of two hundred unselected patients undergoing off-pump versus conventional coronary artery bypass grafting. J Thorac Cardiovasc Surg. 2003;125:797-808.

\section{Discussion}

Dr Robbin G. Cohen (Los Angeles Calif). Tom, that was a nice presentation and I would venture to say that you are preaching to the choir. Still, the benefits of complete myocardial revascularization have recently been challenged by both the interventional cardiology community and cardiac surgeons who have found it necessary to modify their coronary operation to decrease early operative morbidity and mortality. I think that your article has the potential to be important because it reminds us that despite improvements in an area like myocardial protection and increased arterial graft use, IRV still results in decreased survival, and that is basically your take-away message. Having said that, I am concerned about a couple of things that I think cloud your study, and the first is the fact that a significant number of patients who were incompletely revascularized had off-pump CABG early in the operative experience of the authors. The result is that we do not know whether the IRV in the off-pump group was due to patient characteristics, such as diffuse disease or inadequate targets, versus the possibility that they actually had a different type of operation than the on-pump cohort. Therefore my first question is as follows: Which was it that led to the increased rate of incomplete revascularization in the off-pump group, bad disease or a learning curve with a new technical procedure?

Dr Kleisli. Taking into consideration that our study is a retrospective analysis, we are somewhat limited by the information available to us in terms of the decision-making process at the time of the operation. However, I can say that there was significant surgeon bias in terms of selecting which patients received onpump versus off-pump CABG, as well as complete versus incomplete revascularization. As such, we could not really look at it in terms of disease.

Dr Cohen. I was a little confused by your method, and the definition of complete revascularization was when at least one bypass graft was placed distal to a $50 \%$ or greater narrowing in each diseased territory. Now this implies that a patient could have, for example, tight stenoses in both an LAD and a large diagonal artery that you could place a graft to one of those vessels, and in your study you considered that to be completely revascularized. Similarly, a single graft, such as an obtuse marginal territory that had multiple large vessels with disease, would also be considered complete revascularization in your study. My question is, isn't it possible that there were a large number of patients in your completely revascularized group that others might have considered incompletely revascularized, and isn't that what might make your study look different from previous similar studies that actually do not show a difference in fewer grafts in terms of them being revascularized or not?

Dr Kleisli. In regard to our definition, it is a functional classification revascularization. Therefore for a patient to be considered completely revascularized, there needed to be at least 1 graft placed into each territory, for example, 1 graft to the LAD, 1 to the circumflex, and 1 to the right coronary territory.

In regard to the completeness of revascularization, most patients who were completely revascularized received the appropriate amount of grafts into their territories. For example, if a patient 
had disease in the LAD and the circumflex and the right coronary artery and they received 3 grafts, this would be considered appropriate for the number of lesions. However, there were also numerous patients who received more grafts than the number of stenoses that were present, leading them to receive 4 or 5 grafts, which would make them completely revascularized.

Dr Cohen. I understand your answer, but I am not sure that I agree with it, and I still think that your bias was toward calling some patients completely revascularized who really were not. At any rate, $I$ think it is a nice article. It has the potential to be important, and I appreciate the opportunity to discuss it.

Dr Wen Cheng (Los Angeles, Calif). I am one of the surgeons on this study from Cedars-Sinai, and I wanted to tell Dr Cohen how we arrived at the definition of complete revascularization. Vander Salm and colleagues, reviewing the BARI study, looked at 3 or 4 different definitions of completeness of revascularization. Also, multiple other articles, including the Emory study and the Coronary Artery Surgery registry, decided to use a functional classification in which completeness of revascularization was determined by means of complete grafting of each ischemic territory. The BARI study found that if you overgraft the patient (ie, you put 2 grafts into a lateral territory), those patients did worse. Therefore, Thomas and I chose to use a functional classification rather than traditional classification of grafting every single diseased vessel.

Regarding the learning curve, we started doing off-pump operations back in 1995. In 1998, we were doing about $15 \%$ offpump operations; in 1999, 28\%; and in 2000, about 20\%. We elected to focus our experience on the time period of 1998 through 2000 because we were doing off-pump operations in a fairly standardized fashion. We did not have the apical suction stabilizer, for example, but we were using techniques that we were comfortable with, and our learning curve was believed to be less. It does not completely eliminate a learning curve, but I believe that it was minimized. I think the strength of the study is the magnitude of the differences. In many of the other studies, you are talking a 5\% to $10 \%$ survival advantage. In fact, in the Emory study out to 11 years that advantage disappeared. That was due to perhaps their exclusive use of saphenous vein grafting. The magnitude of the advantage here is large: $30 \%$ for all-cause death and $20 \%$ for cardiac death. Therefore, I think the strength of the study-Thomas did an excellent job with this study-is that the magnitude is quite large. Thomas and I reviewed all the charts, and we are comfortable with using a functional definition for completeness of the revascularization.

Dr Anthony Furnary (Portland, Ore). Nicely presented. I have 2 questions. One, I did not see an analysis of how use of the radial artery affected survival, and certainly in an analysis like this, where radial artery use is different in the differing groups, one would need to factor that in in a multivariable analysis. Was that done? Did you do multivariable analysis of the things that actually did affect survival?

Dr Kleisli. Yes, we did perform multivariable analysis. I have some backup slides with this information to show, but we did not specifically look at the radial artery as one of our variables.

Dr Furnary. Did you look at the radial artery as one of the variables?

Dr Kleisli. As of this point, we have not.

Dr Furnary. I think that should be done. Maybe one of you could answer this. What do you think the clinical implications of this study are vis a vis extending our revascularization with wraps to extremely small vessels, the use of transmyocardial laser revascularization, the use of gene therapy?

Dr Kleisli. I think that complete revascularization is still an important concept, regardless of the fact that there are other treatment modalities available to help our patients, such as TMR and all the other techniques you just mentioned. Therefore, I think our take-home message is still important, regardless of the fact that there are other interventional methods to help out the patient.

Dr Daniel Wong (Boston, Mass). This was a really nice study and a very provocative topic. My question is along the same lines. I was quite interested in your abstract that you mentioned that you had done some logistic regression, and I was wondering whether you could comment-this is just from your abstract-that you found that incomplete revascularization was a predictor of death; however, there were other things that predicted that. What happens when you put those into the model? Did the effect of incomplete revascularization go away then?

Dr Kleisli. That depended on our outcome variable. If we look at cardiac death in regard to which variables influenced cardiac death, we found that incomplete revascularization, age, and diabetes were important predictors. However, in regard to all-cause death, incomplete revascularization ended up not being a predictor for this outcome. 

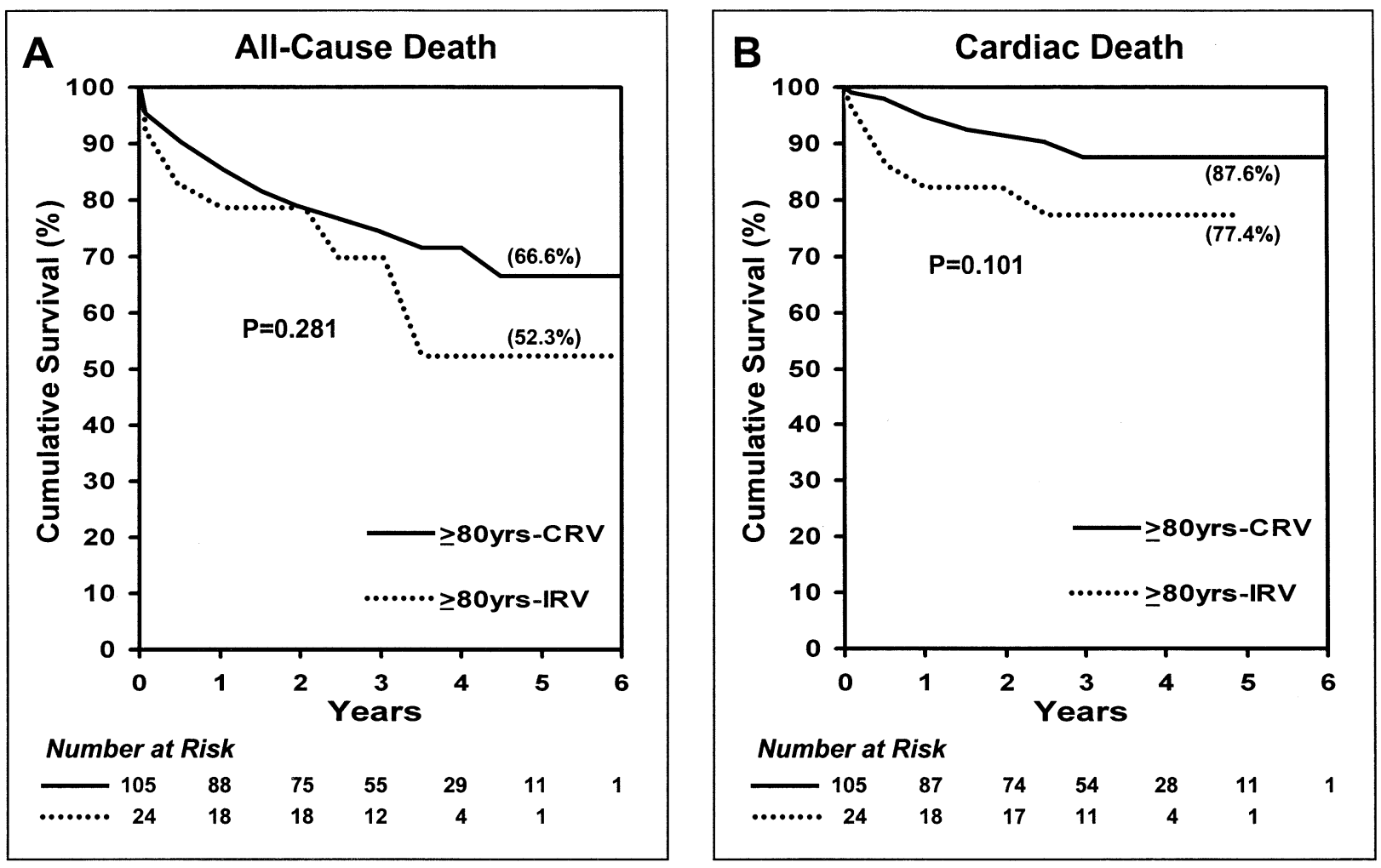

Figure E1. A, Cumulative unadjusted survival from all-cause death in patients with CRV and IRV 80 years of age or older. B, Cumulative unadjusted survival from cardiac death in patients with CRV and IRV 80 years of age or older. Numbers in parentheses (percentages) represent 5-year survival percentages. 

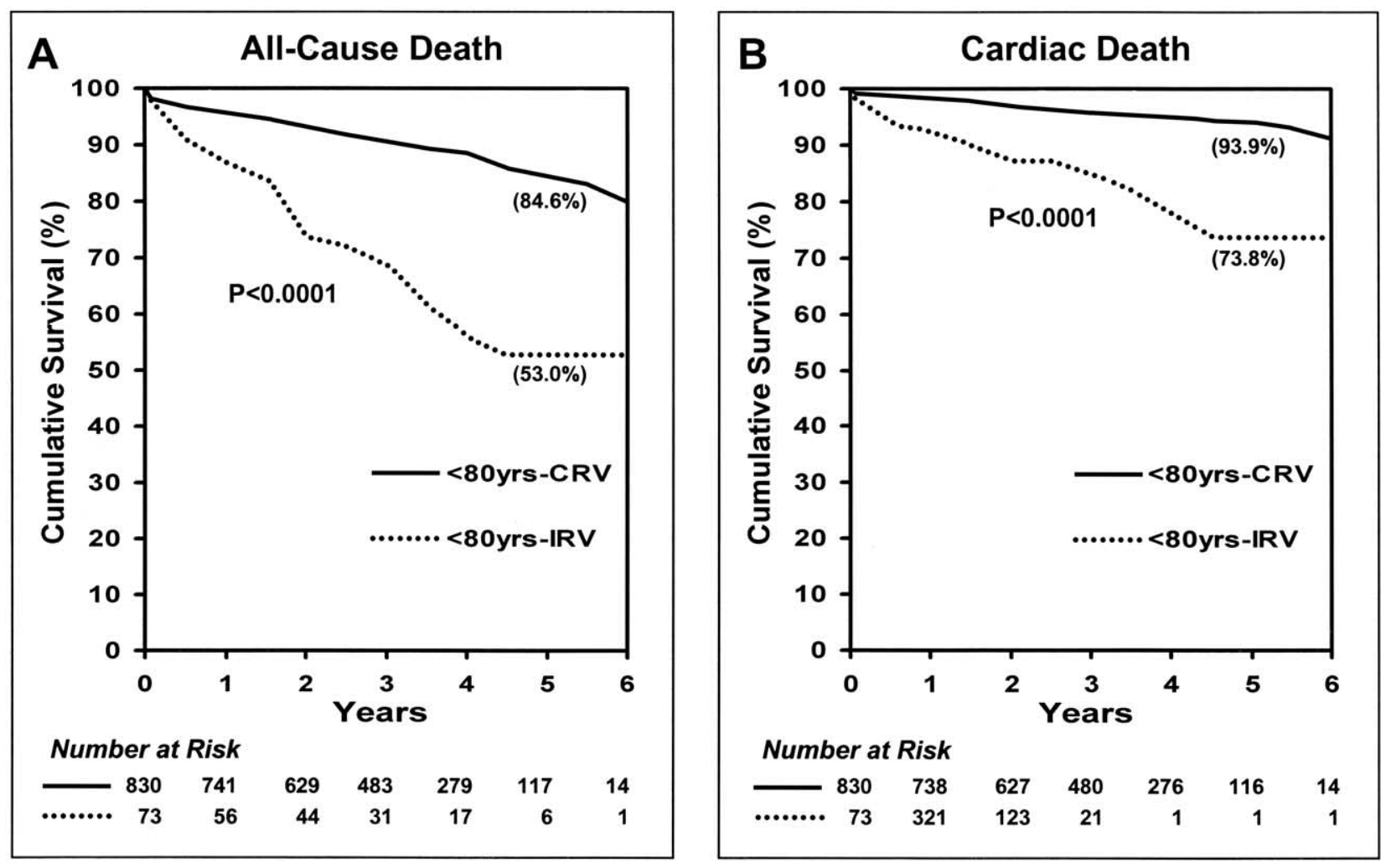

Figure E2. A, Cumulative unadjusted survival from all-cause death in patients with CRV and IRV under 80 years of age. B, Cumulative unadjusted survival from cardiac death in patients with CRV and IRV under 80 years of age. Numbers in parentheses (percentages) represent 5-year survival percentages. 
TABLE E1. Variables entered into multivariable analyses

\begin{tabular}{|c|c|c|}
\hline & Logistic regression & Cox proportional hazard \\
\hline $\begin{array}{l}\text { Incremental risk } \\
\text { factor }\end{array}$ & $\begin{array}{c}\text { Incomplete } \\
\text { revascularization }\end{array}$ & $\begin{array}{c}\text { All-cause and cardiac } \\
\text { death }\end{array}$ \\
\hline Age & $\checkmark$ & $\checkmark$ \\
\hline $\mathrm{EF}$ & $\checkmark$ & $\checkmark$ \\
\hline CHF & $\checkmark$ & $\checkmark$ \\
\hline DM & $\checkmark$ & $\checkmark$ \\
\hline Prior MI & $\checkmark$ & $\checkmark$ \\
\hline HTN & $\checkmark$ & $\checkmark$ \\
\hline Female sex & $\checkmark$ & $\checkmark$ \\
\hline COPD & $\checkmark$ & $\checkmark$ \\
\hline CVA & $\checkmark$ & $\checkmark$ \\
\hline PVD & $\checkmark$ & $\checkmark$ \\
\hline CVA, in-hospital & & $\checkmark$ \\
\hline LM & $\checkmark$ & $\checkmark$ \\
\hline $\begin{array}{l}\text { No. of territories } \\
\text { diseased }\end{array}$ & $\checkmark$ & $\checkmark$ \\
\hline IRV & & $\checkmark$ \\
\hline Pump & $\checkmark$ & $\checkmark$ \\
\hline LITA & & $\checkmark$ \\
\hline RITA & & $\checkmark$ \\
\hline Radial artery & & $\checkmark$ \\
\hline Saphenous vein & & $\checkmark$ \\
\hline Cx territory & $\checkmark$ & \\
\hline RCA territory & $\checkmark$ & \\
\hline
\end{tabular}

$E F$, Ejection fraction; $C H F$, congestive heart failure; $D M$, diabetes mellitus; $M I$, myocardial infarction; HTN, hypertension; COPD, chronic obstructive pulmonary disease; $C V A$, cerebrovascular accident; $P V D$, peripheral vascular disease; $L M$, left main; IRV, incomplete revascularization; Pump, procedure performed with cardiopulmonary bypass; LITA, left internal thoracic artery; RITA, right internal thoracic artery; $C X$, circumflex; $R C A$, right coronary artery.
TABLE E2. Individual patient-recorded reasons for incomplete revascularization

\begin{tabular}{|c|c|c|c|c|c|c|}
\hline \multirow[b]{2}{*}{ Reason } & \multicolumn{2}{|c|}{ IRV } & \multicolumn{2}{|c|}{ IRV On-pump } & \multicolumn{2}{|c|}{ IRV OРCAВ } \\
\hline & $\begin{array}{c}\text { Total } \\
\text { no. }\end{array}$ & $\%$ of 97 & No. & $\%$ of 52 & No. & $\%$ of 45 \\
\hline $\begin{array}{l}\text { Small and/or severe } \\
\text { disease }\end{array}$ & 33 & 34.0 & 24 & 46.2 & 9 & 20.0 \\
\hline Nondominant & 14 & 14.4 & 5 & 9.6 & 9 & 20.0 \\
\hline Infarcted tissue & 12 & 12.4 & 11 & 21.2 & 1 & 2.2 \\
\hline High risk & 12 & 12.4 & 0 & 0.0 & 12 & 26.7 \\
\hline Collaterals & 10 & 10.3 & 4 & 7.7 & 6 & 13.3 \\
\hline $\begin{array}{l}\text { No conduit } \\
\text { available }\end{array}$ & 9 & 9.3 & 4 & 7.7 & 5 & 11.1 \\
\hline No reason & 7 & 7.2 & 4 & 7.7 & 3 & 6.7 \\
\hline Total & 97 & 100 & 52 & 100 & 45 & 100 \\
\hline
\end{tabular}

